\title{
Spontaneous canine hydrocephalus: cerebrospinal fluid dynamics ${ }^{1}$
}

\author{
A. SAHAR, ${ }^{2}$ G. M. HOCHWALD ${ }^{3}$ W. J. KAY,${ }^{4}$ AND J. RANSOHOFF \\ From the Departments of Neurosurgery and Neurology, New York University Medical Center, U.S.A.
}

SUMMARY Cerebrospinal fluid dynamics were studied in 14 dogs with spontaneous hydrocephalus. In nine of the dogs aqueductal obstruction was observed and the remainder had a "communicatingtype' hydrocephalus. The major histological findings consisted of severe ependymal destruction, spongy changes in the periventricular white matter, increased density of capillaries in this area, and varying degrees of thickening, fibrosis, and fusion of the choroid villi. The formation and $\overrightarrow{0}$ absorption of CSF were studied by perfusion of the cerebral ventricles. The rate of formation of $\mathrm{CSF}$ was found to decrease with perfusion pressure by $\mathrm{V}_{\mathrm{f}}=0.02595-0.00022 \mathrm{P} \mathrm{ml} . / \mathrm{min}\left(\mathrm{P}=\mathscr{E}^{2}\right.$ pressure in $\mathrm{cm}_{2} \mathrm{O}$ ). The absorption of spinal fluid was found to increase linearly with pressure by $\mathrm{V}_{\mathrm{a}}=0.0165+0.00050 \mathrm{P}$. The various factors influencing the formation and absorption of the spinal fluid are discussed. The meaning and attainment of 'arrest' of the hydrocephalic process in $\omega$ terms of the measured rates of CSF formation and absorption in these animals are considered.

Spontaneous canine hydrocephalus seems to be a true counterpart of this disease in humans. The clinical course and the gross pathological changes characterizing the disease process and their aetiological classification appear to be similar in both species (Hoerlein, 1965). It seemed, therefore, especially useful to study the pathophysiology of cerebrospinal fluid (CSF) turnover in dogs with naturally occurring hydrocephalus. Such a study would also permit an evaluation of previous observations made on an experimental model of this disease process in the same species (Bering and Sato, 1963; Hochwald, Sahar, Sadik, and Ransohoff, 1969; Sahar, Hochwald, and Ransohoff, 1971). The occurrence of an analogous disease in the dog can be made useful for therapeutic trials such as the evaluation of various types of shunts or other procedures or drugs which would modify CSF formation or absorption.

Towards these ends the bulk formation and absorption of CSF was studied in spontaneous

\footnotetext{
${ }^{1}$ This study is supported by Grants no. NB-06599 and no. 05024 from the USPHS.

'Present address: Department of Neurosurgery, Hebrew-Hadassah Medical School, Jerusalem, Israel.

${ }^{3}$ Dr. Hochwald is a recipient of a Special Research Fellowship Award no. 2 F 11 NB-01431 from the USPHS. (Reprint requests to GMH.) 'Present address: Animal Medical Center, Section of Neurology, Department of Medicine, N.Y.C., N.Y.
}

hydrocephalus in dogs with the aid of the technique of ventricular perfusion. An attempt was made t8 describe some of the pathological anatomic $\triangle$ changes as well as to compare the physiologicie $\overrightarrow{0}$ data with those obtained previously with kaolin? induced hydrocephalus in dogs and cats.

\section{MATERIALS AND METHODS}

Fourteen dogs of various breeds formed the basis of this $\frac{\mathscr{O}}{\Phi}$ study. These included five French poodles, two toy $\varrho$ bulldogs, two German shepherd dogs, one English pug, $\overrightarrow{\overrightarrow{0}}$ one Lhasa Apso, and one dog of a mixed breed. Chi- $\frac{3}{3}$ huahuas, which are known to have large ventricles, were excluded from this group as the ventriculomegaly is apparently non-progressing and is not associated with neurological signs. The ages of the animals ranged between 4 and 14 months.

In most dogs the clinical diagnosis was obvious because of the large size of the head, the presence of a frontal dome, open fontanelles, the 'sunset' phenomenon $\delta$ of the eyes, etc. In the rapidly progressing cases there was loss of coordination, progressive ataxia, spasticity, $\mathrm{O}$ occasional opisthotonos, and general inappetence and somnolence. The older dogs showed no apparent neuro- $\frac{D}{O}$ logical signs except difficulty in training. In all dogs the diagnosis was confirmed by air ventriculography. Ventri- N culography also aided in geometrically estimating os ventricular volumes.

The rates of bulk formation and absorption of spinal fluid were measured with the method of lateral ventricle- 
to-lateral ventricle perfusion (Hochwald et al.,1969). Short cannulas (18-gauge) were introduced into each lateral ventricle through small burr holes in the skull. Penetration of the ventricle was without difficulty, and was indicated by the immediate flow of spinal fluid through the cannula. One cannula was connected to an infusion pump which delivered perfusion fluid at a constant rate in each experiment $(0.185 \mathrm{ml} . / \mathrm{min}$ to $0.742 \mathrm{ml} . / \mathrm{min}$ according to the estimated size of the ventricular system). The perfusion pressure was regulated by the height of the outflow tubing. The pressure was measured throughout the experiment with the aid of a P 23BB Statham transducer connected in parallel to the inflow system at the level of the interaural line and constantly monitored. Outflow fluid was collected at 10 minute intervals and the outflow volumes determined gravimetrically. Each perfusion experiment was carried out until steady-state was reached, usually four to six hours.

The perfusion fluid was an artificial spinal fluid containing inulin $(40 \mathrm{mg} / 100 \mathrm{ml}$.) and radioiodinated serum albumin ( $\left.{ }^{131} \mathrm{I}-\mathrm{CSA}\right)$ (Hochwald and Wallenstein, 1967). Inulin determinations were done according to the resorcinol method (Schreiner, 1950). Radioactivity was measured in a well-type scintillation counter (Nuclear Chicago). From inulin or ${ }^{131}$ I-CSA dilutions and differences between inflow and outflow volumes at steady-state, it was possible to calculate the rates of formation and absorption of CSF (Sahar, Hochwald, Sadik, and Ransohoff, 1969b). The ventricular volumes were calculated as described previously (Sahar et al., 1969b).

All experiments were performed without general anaesthesia. The dogs were given intermittent intravenous injections of Acepromazine (diethylamino-propyl-phenothiazin-2-methyl ketone, Ayerst Laboratories, N.Y.). Occasionally it was necessary to supplement this with small doses of Surital (sodium thiamylal, Parke, Davis $\&$ Co.). The dogs were in a tranquillized state throughout the experiment and drank and ate immediately after its termination. In this way it was possible to use one dog for as many as four perfusion experiments.

At the end of the final experiment the dog was killed by exsanguination. The brain was removed and fixed in $10 \%$ phosphate buffered formalin. Histological preparations were made from representative areas of the brain.

\section{RESULTS}

\section{ANATOMICAL FINDINGS}

1. GROSS CHANGES The ventricular volumes (measured as distribution volumes of ${ }^{131}$ I-CSA and verified by fluid drainage post mortem), ranged between $16.5 \mathrm{ml}$. and $78 \mathrm{ml}$. Atrophy of the cerebral mantle varied from moderate to extreme and affected mostly the white matter (Fig. 1). Of the 14 dogs, seven had severe aqueductal stenosis and two had no detectable aqueduct. In all these animals the fourth ventricle was normal in appearance. The other five dogs had communicating hydrocephalus the anatomico-pathological cause of which could not be established. Rupture of the septum pellucidum was a frequent finding.

In all the enlarged ventricles the choroid plexus was relatively small, thin, and stringy rather than having its usual drape-like, multi-folded appearance In some cases the plexus was difficult to identify This was in striking contrast with the normal appear-

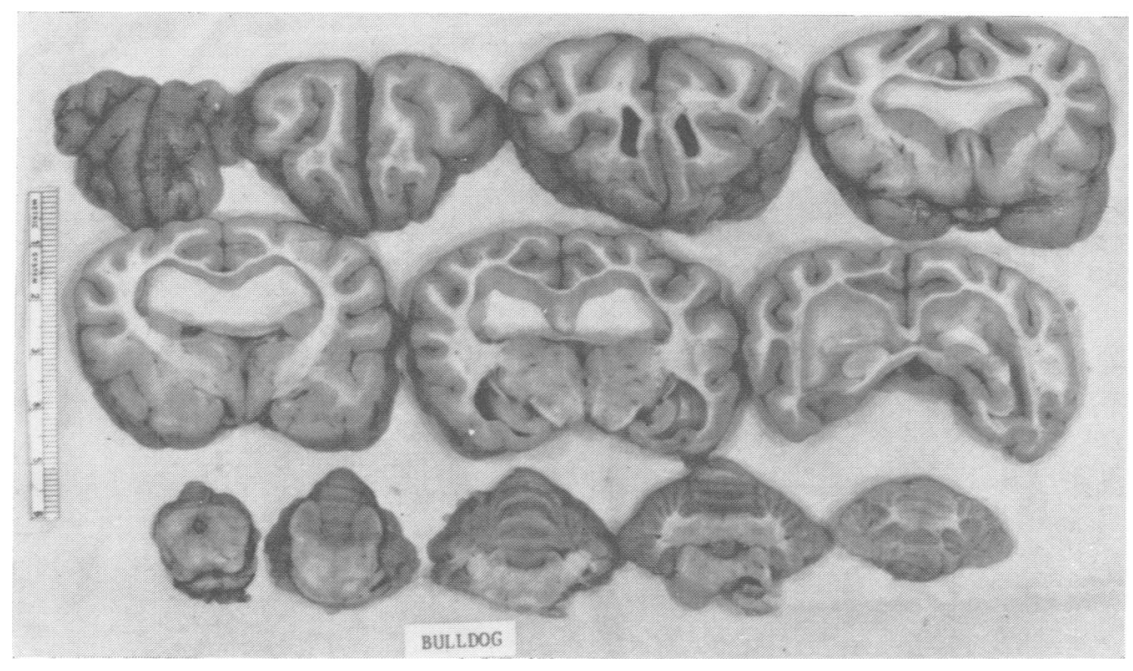

FIG. 1. Coronal section through the brain of dog with 'communicating' hydrocephalus. There is atrophy of the cerebral mantle with thinning of white matter. Because of the absence of midline structures, the enlarged ventricles are in open communication with each other. 
ance of the choroid plexus of the fourth ventricle in the dogs with aqueductal stenosis or atresia.

2. LIGHT MICROSCOPY Histologically, the severest changes were observed in the lining ependyma and periventricular white matter. The ependyma was largely absent; in areas where it was still recognizable it was severely flattened. In several of the dogs with communicating hydrocephalus the ependymal lining was spared on the dorsal aspect of the aqueduct while the ventral aspect was denuded. The larger extent of the ventricular surface contained collections of glial cells which sometimes formed microscopical elevations into the lumen. Extending into the white matter to a variable distance were irregular cavities which gave the tissue a spongy appearance. The cavities were clear and did not seem to contain any proteinaceous material (Fig. 2). The walls and ependymal lining of the fourth ventricle in the dogs with aqueductal stenosis had a normal appearance.

The number or density of small blood vessels seemed to be increased in the ventricular walls. These were mainly capillaries of variable diameter, lying close to each other within the first several hundred microns beyond the ventricular wall (Fig. 3).

The aqueductal stenosis left sometimes only a microscopic single slit-like channel (Fig. 4A). In other cases it was replaced by a number of tubular structures consisting of rosettes of ependymal cells (Fig. 4B).
As mentioned above, the choroid plexus seemed atrophied. In some specimens, in spite of the $\mathbb{\Phi}$ apparent reduction in size, no structural changes were observed. In the majority of the cases, however, on the choroid villi were less numerous, thicker and club-like instead of having the usual delicate $D$ finger-like appearance. In many preparations the villi seemed to be fused (Fig. 5A). The epithelial lining was at times flattened and even frayed. The core of the thickened villi consisted of connective tissue that sometimes was rather dense. In many instances the walls of the blood vessels were $\frac{7}{0}$ markedly thickened. In several specimens the choroid plexus consisted of a cluster of thick-walled $\bar{c}$ blood vessels with abundant connective tissue $\overrightarrow{\mathbb{D}}$ between them and lined only on the outer border $\triangle$ by choroid epithelium (Fig. 5B).

\section{CEREBROSPINAL FLUID DYNAMICS}

1. PRESSURE The ventricular pressure measured at $\bar{\omega}$ the time of penetration of the ventricles ranged between $5 \mathrm{~cm} \mathrm{H}_{2} \mathrm{O}$ and $15 \mathrm{~cm} \mathrm{H}_{2} \mathrm{O}$ (mean $12 \mathrm{~cm} \frac{5}{0}$ $\mathrm{H}_{2} \mathrm{O}$ ).

2. RATE OF FORMATION OF CSF The rate of formatio $\omega$ of CSF was calculated from the dilution of inul $\infty$ (and ${ }^{131} \mathrm{I}-\mathrm{CSA}$ ) during steady-state lateral ventricl兽으 to-lateral ventricle perfusion. The type of hydro cephalus could be determined with certainty only $c$ at necropsy. After careful consideration of the dagi

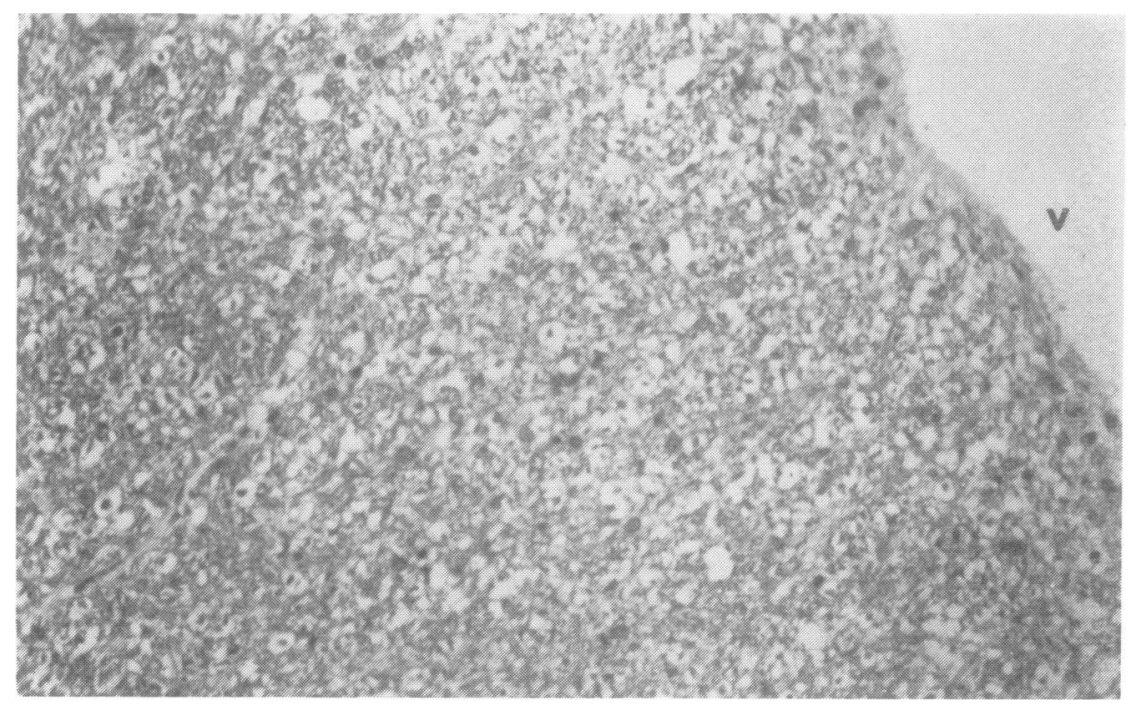

FIG. 2. Lateral ventricle (V) and periventricular white matter including ventricular lining from which ependymal cells are missing. Note irregular cavities giving a spongiform appearance. $H$ and $E, \times 400$. 


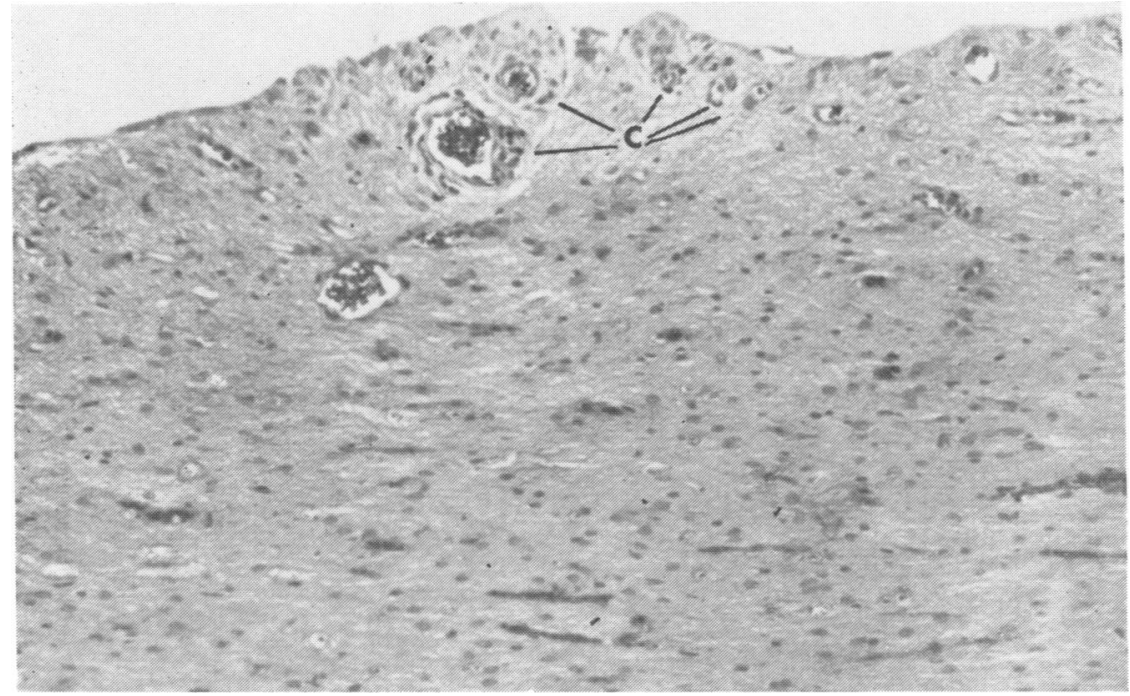

FIG. 3. Vascularization of subependymal region. Capillaries (C) are generally large and numerous. $H$ and $E, \times 322$.
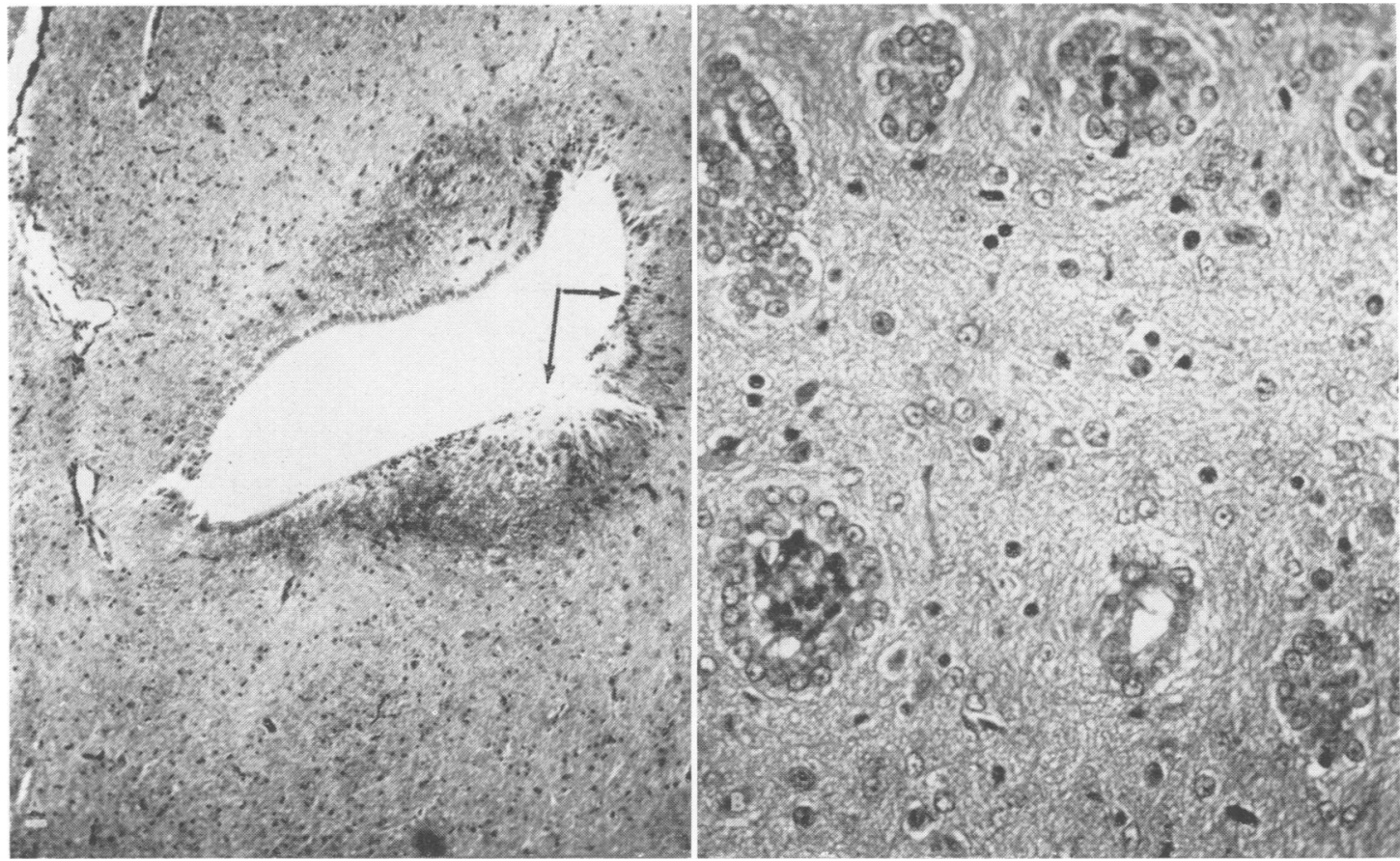

FIG. 4. (a) Transverse section of mid-brain showing stenosis of the aqueduct. No inflammatory cells noted. Ependymal lining is incomplete $(\uparrow) . H$ and $E, \times 300 . \quad(b)$ Transverse section at the level of the aqueduct. Aqueduct is replaced by aggregations of ependymal ceils, many of which form tubules ('rosettes'). Some appear to form channels which are lined with ependymal cells. Minimal amount of gliosis in adjacent tissue. $H$ and $E, \times 77$. 

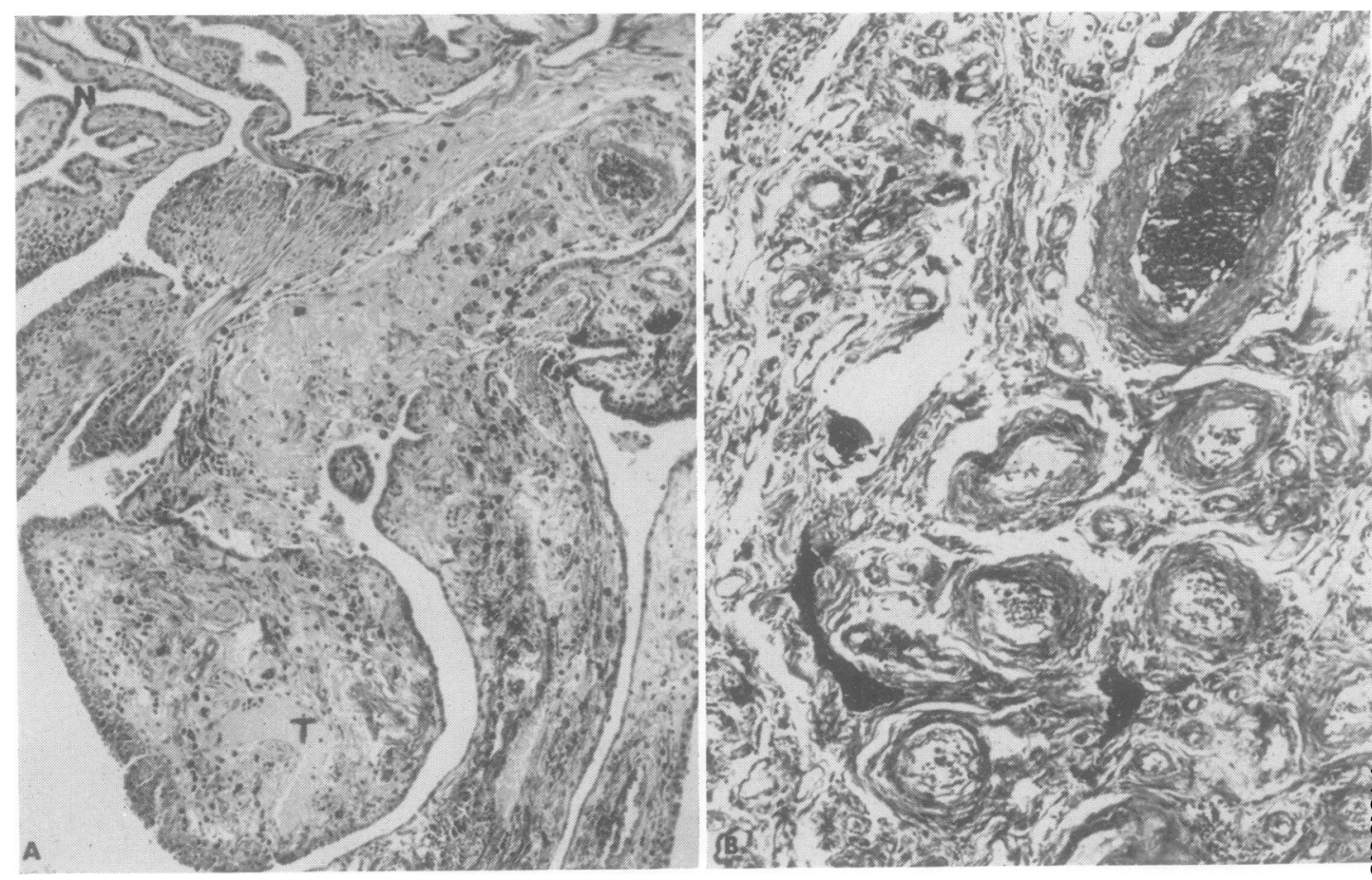

FIG. 5. (A) Thickened choroid plexus with loss of surface area due to fusion of villi. Compare relatively normal content $\frac{\Omega}{\mathrm{Q}}-$ connective tissue $(\mathrm{N})$ with increased amount in thickened villi $(\mathrm{T}) . H$ and $E, \times 385$. (B) Remnants of choroid plexus asc a cluster of blood vessels which are separated from each other by abundant connective tissue. $H$ and $E, \times 300$.

no significant differences in the rates of formation and absorption of CSF were found between dogs with either aqueduct stenosis or communicating hydrocephalus. The rates obtained in 11 perfusion experiments varied between 0.0101 and 0.0269 $\mathrm{ml} . / \mathrm{min}$. These variations were not related to the weight of the animal or to the size of its ventricles. There was, however, a good correlation between the rate of formation of CSF and the perfusion pressure. Figure 6 shows the effect of pressure on formation rate $\left(V_{f}\right)$ in one dog perfused at four different pressures. The rate of secretion of spinal fluid is seen to decline with increase in pressure. A similar relationship was calculated for the whole group studied. The line of regression was found to be $V_{f}=0.02595( \pm 0.003316)-0.000223 \mathrm{P} \mathrm{ml} . / \mathrm{min}$ $\left(\mathrm{P}=\right.$ pressure in $\left.\mathrm{cm} \mathrm{H}_{2} \mathrm{O}\right)$.

Because of the large size of the ventricles, it was not feasible to reach steady-state at more than one pressure during one perfusion experiment (Sahar, Hochwald, and Ransohoff, 1970; Hochwald and Sahar, 1971).

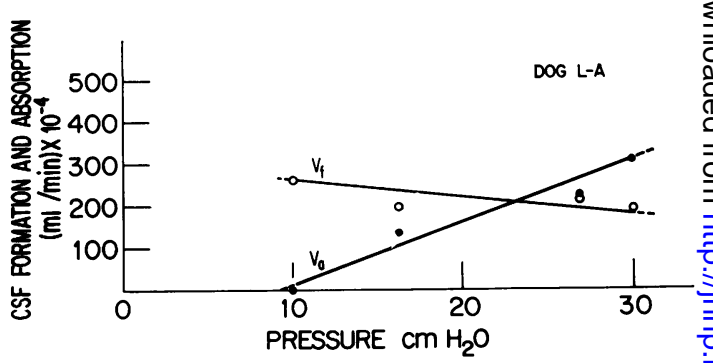

FIG. 6. Rates of formation $\left(V_{\mathrm{f}}\right)$ and absorption $\left(V_{a}\right) \frac{\mathrm{O}}{3}$ of CSF in one dog perfused four times under different; pressures. Note the good correlation between pressure and $\frac{}{3}$ both absorption and formation.

3. ABSORPTION OF CSF Absorption of cerebrospinalo fluid was measured as inulin clearance at steady $\sim 0$ state perfusion. The rates of absorption varied as an function of perfusion pressure from 0 to $0.0471^{\omega}$ 
$\mathrm{ml} . / \mathrm{min}$. The relationship between absorption rate $\left(\mathrm{V}_{\mathrm{a}}\right)$ and pressure could be expressed by the regression line $V_{a}=0.0165( \pm 0.00863)+0.000497$ $\mathrm{P} \mathrm{ml} . / \mathrm{min}$. This is to say that an elevation of perfusion pressure by $1 \mathrm{~cm} \mathrm{H}_{2} \mathrm{O}$ increases CSF absorption by $0.5 \mu \mathrm{l} . / \mathrm{min}$. Such linear dependence of absorption on pressure could be demonstrated both in the individual animal perfused at different pressures (Fig. 6, $V_{a}$ ) and for the whole group (Fig. 7). No differences could be detected between the communicating and obstructive hydrocephalic animals in regards to absorption of CSF. That clearance was true absorption was verified by the recovery from the serum of appropriate amounts of ${ }^{131}$ I-CSA (Sahar et al., 1969b).

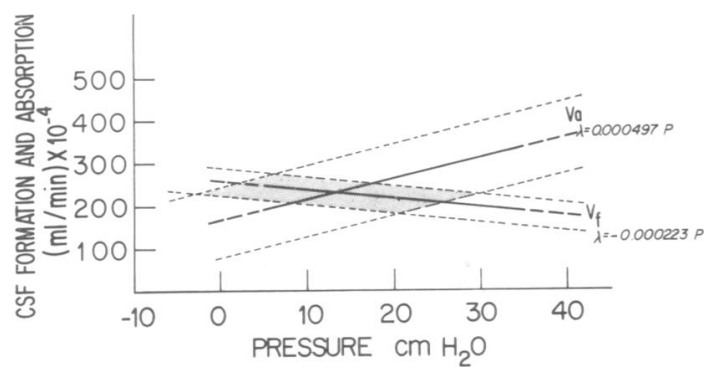

FIG. 7. Lines of regression of absorption $\left(V_{a}\right)$ and formation $\left(V_{f}\right)$ of CSF. Interrupted lines $= \pm S E$. Numbers are the regression coefficients. Shaded area represents the theoretical range of pressures and rates of formation and absorption in which equilibrium may take place.

\section{DISCUSSION}

The present work was meant to compare some of the structural changes in the spontaneously hydrocephalic dogs with those found by others in animals with experimental hydrocephalus and in human hydrocephalus. It was also aimed at directing attention to morphological changes with regard to their possible role in the pathophysiology of this disease state.

The changes found in these dogs with spontaneous hydrocephalus are similar to those described previously in experimentally induced hydrocephalus in dogs and in other species (De, 1950; Johnson and Johnson, 1968; Hochwald et al., 1969; Weller and Wiśniewski, 1969a, b) and in human hydrocephalus (Hassin, 1930; Russell, 1949; Kwitnitsky-Ryjov, 1961). Since the aetiological factors leading to hydrocephalus were different it would be logical to assume that many of the pathological changes are the result of a common denominator, such as intraventricular pressure.

The most prominent findings observed in the ventricular wall were the loss of the ependymal lining, the clear sponge-like cavities, and the density of the blood vessels. It seemed of interest to try to correlate these changes with the development of an alternative, transventricular route for CSF absorption. Other observations from this laboratory suggested that the process of transventricular absorption actually took place within the layers closest to the ventricular cavity (Sahar, Hochwald, and Ransohoff, 1969a) and possibly within the first $1 \mathrm{~mm}$ of brain tissue (Lux, Hochwald, Sahar, and Ransohoff, 1971). It was also shown that with increase in perfusion pressure there was an increase in the water content and the inulin space within the first $1 \mathrm{~mm}$ of brain adjacent to the ventricle (Lux et al., 1971). It is therefore conceivable that the cavities in the white matter proximal to the ventricular lumen are the morphological substrate of this increased extracellular space. They may also be the channels through which the CSF flows to be absorbed by the blood vessels within the brain substance.

Numerous blood vessels in proximity to the ventricle have also been observed. The increase may only be apparent due to the differential atrophy of brain tissue proper, or they may represent preexisting blood vessels that have become prominent due to active or passive congestion. Their location, number, and size may be factors in enhancing the absorption of CSF.

The present findings seem to reaffirm previous conclusions concerning the absorptive capacity in experimental hydrocephalus (Sahar et al., 1969b, 1971). The line of regression, which is the mathematical expression of the relationship between absorption and perfusion pressure, was similar. The value in the spontaneously hydrocephalic dogs was $\mathrm{V}_{\mathrm{a}}=0.0165+0.00049 \quad \mathrm{P} \mathrm{ml} . / \mathrm{min} \quad(\mathrm{P}=$ pressure in $\mathrm{cm} \mathrm{H}_{2} \mathrm{O}$ ). This value in normal dogs was found to be $\mathrm{V}_{\mathrm{a}}=0.0390+0.00063 \mathrm{P} \mathrm{ml} . / \mathrm{min}$ (Sahar et al., 1971). The smaller intercept value $(0.0165)$ indicates a higher initial resistance to absorption (Sahar, 1969b). The smaller value of the slope $(0.00049)$ represents an increase in the absorptive capacity with pressure which is only $25 \%$ less than in the normal dog.

The morphological changes occurring in the choroid plexus attracted very little attention in the past (Hassin, 1930; Russell, 1949) or were denied (Tennyson and Pappas, 1961). The findings in these dogs, however, are very similar to those in experimental hydrocephalic cats (Hochwald et al., 1969). The thickening and fusion of the villi seemed greatly 
to reduce the total surface area of choroid plexus. This (Heisey, Held, and Pappenheimer, 1962; Bering and Sato, 1963), together with the damage to the choroidal epithelium and the changes in the choroidal blood vessels and their distance from the surface, may possibly be in part responsible for the decrease in the rate of formation of CSF in the naturally occurring hydrocephalic dog.

The mean rate of formation of cerebrospinal fluid in these dogs was $0.0218 \mathrm{ml} . / \mathrm{min}$. This would constitute a decrease in secretion of CSF as compared with the rates previously reported for normal dogs (Sahar et al., 1971). The structural changes themselves could not explain this decrease in production of CSF. Such changes would produce a constant reduction in secretion. The data, however, show that CSF production is inversely proportional to ventricular pressure. This relationship was shown to be $V_{\mathrm{f}}=0.02595-0.000223 \mathrm{P} \mathrm{ml} . / \mathrm{min} \quad(\mathrm{P}=$ $\mathrm{cm} \mathrm{H}_{2} \mathrm{O}$ ). The adverse influence of pressure on CSF formation, as shown previously (Sahar et al., 1970), seems to indicate the action of another mechanism capable of limiting CSF formation. This was also shown to occur in the normal calf (Calhoun, Hurt, Eaton, Rousseau, and Hall, 1967) and rabbit (Hochwald and Sahar, 1971) where there was no reason to believe that structural changes in the choroid plexus were present. As suggested previously (Sahar et al., 1970, 1971; Hochwald and Sahar, 1970) such a dynamic factor may conceivably be a change in blood flow in the CSF-forming organs. Although the intracranial pressure in the range employed in these experiments seemingly does not affect cortical blood flow (Greenfield and Tindall, 1965; Häggendal, Löfgren, Nilsson, and Zwetnow, 1969) it may none the less affect the blood flow in the choroid plexus which is surrounded by CSF. Any changes in CSF pressure are directly transmitted without attenuation to the choroid plexus, and may therefore affect the vascular-to-ventricular pressure gradient which is probably partly responsible for the production of CSF.

Of great interest is the relatively low ventricular pressure measured in these animals. A possible explanation for this may be found in comparing the rates of formation and absorption of CSF in these animals (Fig. 7). Since an increase in perfusion pressure causes an increase in CSF absorption and a decrease in CSF formation, a new equilibrium may be ultimately attained. The shaded area in Fig. 7 shows the pressure ranges in which such an equilibrium can occur. Moreover, it can exist even at relatively low ventricular pressures. This finding may possibly bear a relationship to certain variants of human hydrocephalus. Intraventricular pressure which may be considered well within the normal range is not a rare finding in even uncompensated human hydrocephalus in both infants and adults (Adams, Fisher, Hakim, Ojemann, and Sweet, 1965; Norrel, Wilson, Howieson, Megison, and Bertan, $\stackrel{?}{=}$ 1969). The observation of a relatively low pressure $\widehat{\theta}$ in any patient may indicate an approximation to a 0 new equilibrium due to increase in absorption and decrease in formation of cerebrospinal fluid.

The authors thank Miss J. Brown, BSc., and S. Sullivan for their technical assistance.

\section{REFERENCES}

Adams, R. D., Fisher, C. M., Hakim, S., Ojemann, R. G., Фृ and Sweet, W. H. (1965). Symptomatic occult hydrocephalus with 'normal' cerebrospinal-fluid pressure: A $\backsim$ treatable syndrome. New Engl. J. Med., 273, 117-126.

Bering, E. A., Jr., and Sato, O. (1963). Hydrocephalus: Changes in formation and absorption of cerebrospinal $\vec{\omega}$ fluid within the cerebral ventricles. J. Neurosurg., 20, 1050-1063.

Calhoun, M. C., Hurt, H. D., Eaton, H. D., Rousseau, J. E., Jr., and Hall, R. C., Jr. (1967). Rates of formation and absorption of cerebrospinal fluid in Holstein male $\omega$ calves. Univ. of Conn., Coll. of Agr. Exp. Sta. Bull., 40 pp. 1-22.

De, S. N. (1950). A study of the changes in the brain experimental internal hydrocephalus. $J$. Path. Bacto 62, 197-208.

Greenfield, J. C., Jr., and Tindall, G. T. (1965). Effect acute increase in intracranial pressure on blood flow in the internal carotid artery of man. J. clin. Invest., $4 \frac{9}{7}$ 1343-1351.

Häggendal, E., Löfgren, J., Nilsson, N. J., and Zwetnow, (1969). Influence of induced changes in the cerebrospinat fluid pressure on the cerebral blood flow of dogs. In: Research on the Cerebral Circulation, Third International Salzburg Conference, pp. 275-285. Edited by J. S. Meyer, § H. Lechner, and O. Eichhorn. Thomas: Springfield, Ill.

Hassin, G. B. (1930). Hydrocephalus: Studies of the pathology and pathogenesis with remarks on the cerebrospinal 은 fluid. Arch. Neurol. Psychiat. (Chic.), 24, 1164-1186.

Heisey, S. R., Held, D., and Pappenheimer, J. R. (1962). Bulk flow and diffusion in the cerebrospinal fluid system $\underline{\vec{\sigma}}$ of the goat. Amer. J. Physiol., 203, 775-781.

Hochwald, G. M., and Wallenstein, M. (1967). Exchange of albumin between blood, cerebrospinal fluid, and brain in $\frac{7}{0}$ the cat. Amer. J. Physiol., 212, 1199-1204.

Hochwald, G. M., Sahar, A., Sadik, A. R., and Ransohoff, J. (1969). Cerebrospinal fluid production and histological $\frac{7}{7}$ observations in animals with experimental obstructive 0 hydrocephalus. Exp. Neurol., 25, 190-199.

Hochwald, G. M., and Sahar, A. (1971). The effect of spinal fluid pressure on cerebrospinal fluid formation in rabbits. 응 (Submitted for publication.)

Hoerlein, B. F. (1965). Canine Neurology, pp. 287-297. 응 Saunders: Philadelphia.

Johnson, R. T., and Johnson, K. P. (1968). Hydrocephalus $D$ following viral infection: The pathology of aqueductal 을 stenosis developing after experimental mumps virus $\mathrm{N}$ infection. J. Neuropath. exp. Neurol., 27, 591-606.

Kwitnitsky-Ryjov, Y. N. (1961). The problem of oedema and swelling of the cortical substance in occlusive hydrocephalus (Russian). Zh. Nevropat. Psikhiat., 61, 848-854. N Lux, W. E., Jr., Hochwald, G. M., Sahar, A., and Ranso- 
hoff, J. (1971). Periventricular water content: Effect of pressure in experimental chronic hydrocephalus. Arch. Neurol. (Chic.), 23, 475-479.

Norrell, H., Wilson, C., Howieson, J., Megison, L., and Bertan, V. (1969). Venous factors in infantile hydrocephalus. J. Neurosurg., 31, 561-569.

Russell, D. S. (1949). Observations on the Pathology of Hydrocephalus. Spec. Rep. Ser. med. Res. Coun. (Lond.), No. 265, 1-138.

Sahar, A., Hochwald, G. M., and Ransohoff, J. (1969a). Alternate pathway for cerebrospinal fluid absorption in animals with experimental obstructive hydrocephalus. Exp. Neurol., 25, 200-206.

Sahar, A., Hochwald, G. M., Sadik, A. R., and Ransohoff, J. (1969b). Cerebrospinal fluid absorption in animals with experimental obstructive hydrocephalus. Arch. Neurol. (Chic.), 21, 638-644.

Sahar, A., Hochwald, G. M., and Ransohoff, J. (1970). Experimental hydrocephalus: Cerebrospinal fluid for- mation and ventricular size as a function of intraventricular pressure. $J$. neurol. Sci., 11, 81-91.

Sahar, A., Hochwald, G. M., and Ransohoff, J. (1971). Cerebrospinal fluid turnover in experimental hydrocephalic dogs. Neurology (Minneap.), 21, 218-224.

Schreiner, G. E. (1950). Determination of insulin by means of resorcinol. Proc. Soc. exp. Biol. Med., 74, 117-120.

Tennyson, V. M., and Pappas, G. D. (1961). Electronmicroscopic studies of the developing telencephalic choroid plexus in normal and hydrocephalic rabbits. In: Disorders of the Developing Nervous System, pp. 267-318. Edited by W. S. Fields, and M. M. Desmond. Thomas: Springfield, Ill.

Weller, R. O., and Wiśniewski, H. (1969a). Histological and ultrastructural changes with experimental hydrocephalus in adult rabbits. Brain, 92, 819-828.

Weller, R. O., Wiśniewski, H., Ishii, N., Shulman, K., and Terry, R. D. (1969b). Brain tissue damage in hydrocephalus. Dev. Med. child. Neurol., Suppl. 20, 1-7. 